\title{
Lignin Black Liquor in Chemical Enhanced Oil Recovery: A Review for Sacrificial Agent
}

\author{
Sulaiman WRW, Abbas $\mathrm{AH}^{*}$, Jaafar $\mathrm{MZ}$ and Idris AK \\ Faculty of Chemical and Energy Engineering, University of Technology Malaysia, Malaysia
}

\begin{abstract}
Enhance oil recovery (EOR) technique has been long used in residual oil recovery. Chemical EOR is emerging as a vital technology to recover additional residual oil through several mechanisms. The selection of high performance chemical for EOR is a challenging and time consuming task. Chemical EOR has been under spotlight for decades with enormous research efforts for specific reservoir applications. The research efforts reached its pinnacle with the development of surfactant families and formulation rules as well as the use of lignin from black liquor waste as surfactant or sacrificial agent. This complex chain of hydrocarbon and heavy molecular weight lignin, attribute to its high performance as surfactant. Moreover, lignin is a natural product; thus makes it as a low cost chemical. This review paper emphasizes on the importance of lignin in chemical EOR. The current trends and issues on its utilisation and its importance as an environmental sustainable biodegradable polymer matrix are discussed thoroughly. It is hope that this study will increase the research-based culture in lignin-based polymer composites; thus lead to generation of new ideas in the domain.
\end{abstract}

Keywords: EOR; Lignin; Adsorption; Biodegradable

\section{Introduction}

There are three stages in recovering oil from reservoir. In the primary stage, less than $20 \%$ oil were recovered from the original oil in place. Secondary recovery is used when there is insufficient underground pressure for left over oil [1,2]. Most of a reservoir's oil remains in place after the natural energy pressurizing the reservoir has been dissipated. Several techniques for injecting fluids into an oil reservoir to augment the natural forces have been widely used for many years. Such fluid injection is generally recognized as secondary recovery. Nevertheless, many reservoirs still jump to their last stage in less than fifteen years, which requires the application of tertiary recovery techniques after secondary oil recovery attempts [3-5]. The chemical flooding or chemical EOR is applied to recover the residual oil after water flooding. The process involves the use of surfactant/ polymer, polymer, and alkaline flooding. In chemical flooding, surfactants are used to increase the capillary number by lowering the interfacial tension between the aqueous and oil phases. A suitable surfactant should lower the interfacial tension to $\left(10^{-5}\right.$ or $\left.10^{-4}\right)$, which is accomplished by the disturbance of the oil and water molecules [1,68]. Chemical EOR has been under the spotlight for decades and has been attracting academic research attention particularly in the area of specific reservoir applications. Several studies have attempted to address the chemical flooding challenges using chemical adsorption to preserve the concentration of effective groups during flooding [911]. Empirical findings suggest that surfactants have the ability to perform in multi salinity reservoirs with less adsorption and work in high temperatures [12-14]. However, it is not always possible to find the suitable surfactant for the reservoir condition to work. Thus, in a bid to minimize surfactant adsorption, the term "sacrificial agent" appeared. Sacrificial agents are substances that mitigate the adsorption of surfactants into a formation. It also helps to reduce the retention of the surfactant inside the formation $[12,15]$. The sacrificial agent acts to modify the surface formation or be kept in the formation to reduce or eliminate the adsorption of the surfactant $[6,10,16]$. Compares to surfactant, the sacrificial agents are cheaper and thus cost-effective. Alkali, lignosulfonates, cellulose and cellulose derivatives, starch and starch derivatives, low cost surfactant and polybasic carboxylic acids
$[15,17,18]$ are among the sacrificial agents used in the chemical EOR. Although each has their advantages over the other, recent studies suggest lignin as the most sought after sacrificial agent for a host of reasons including its renewable and sustainable property, environmental friendly, readily available in commercial quantity and very affordable $[19,20]$. This review paper therefore highlights the various derivatives and different applications of lignin as a sacrificial agent for chemical EOR. It summarizes the recent advances and issues involved in utilising lignin for new polymer composite materials development. It begins by classifying lignin based on its different derivatives, functions, applications, extraction methods and finally highlights why it is the ideal candidate as the most environmental sustainable and renewable form of biodegradable polymer matrices.

\section{Derivatives of Lignin}

Lignin or lignum meant wood in Latin. In the plant world, lignin is the second abundant and important element. Lignin is a renewable material that can replace the petrochemical in energy and raw fabric industries [21]. Research on the feasibility of lignin as polymer materials has been over 30 years and many properties about lignin were discovered throughout the years. It can be obtained easily, abundance, contain aromatic structure and can be modified in various way makes lignin attractive materials to polymer scientist. However, its complex structure may pose some challenge in its application. Furthermore, lignin is highly dependent on both the botanic origin and the isolation techniques.

"Corresponding author: Abbas AH, Faculty of Chemical and Energy Engineering University of Technology Malaysia, Malaysia, Tel: 00601123181621; E-mail: azzahashim2008@gmail.com

Received August 24, 2016; Accepted September 03, 2016; Published September 11,2016

Citation: Sulaiman WRW, Abbas AH, Jaafar MZ, Idris AK (2016) Investigating the Lignin Black Liquor in Chemical Enhanced Oil Recovery: A Review for Sacrificial Agent. J Pet Environ Biotechnol 7: 298. doi: 10.4172/2157-7463.1000298

Copyright: (c) 2016 Sulaiman WRW, et al. This is an open-access article distributed under the terms of the Creative Commons Attribution License, which permits unrestricted use, distribution, and reproduction in any medium, provided the original author and source are credited. 
Wood generally comprises of cellulose, hemicelluloses and lignin. The quantities differ depending on the type of wood. Phenyl propane units (coniferyl alcohol and sinapyl alcohol) made up the hardwood, while substantial amount of p-coumaryl alcohol units together with coniferyl alcohol made up the softwoods. Free phenolic group on the other hand is the functional group for lignin (Figure 1) [22].

The structure of lignin is complex, but today, the structural elements are quite well known. Due to its hydrophilic nature, the lignin system is sensitive to high clay content. Clay content represents a key risk factor or failure mechanism for this system. The lignin phenol is manufactured from black liquor, a by-product of pulp mills. There are many steps involve in lignin processing: isolation, liquefaction and sulfonating. Despite the attempts made by several researchers to define lignin in terms of its chemical structure, there is still no acceptable definition. The conversion of lignin into valuable products is one way to unleash lignin's potential. For example, technical lignins such as Kraft lignin, lignosulphonates, and soda lignin, which are readily available in large amounts, are considered as a potentially interesting raw material because they are produced in processes dealing with the treatment of lingo-cellulosic materials [23,24].

Lignin is an undefinable compound. It can be used in surfactant system without the need to modify it. The modification process is costly; thus currently, the need to find a way to avoid modification step has led to the use of unmodified Kraft lignin, water soluble sulfonate, and the oil-soluble organic amine blending for chemical EOR.

\section{Lignin by Kraft Process}

Pulping process in paper mills is one of the mostly used methods to extract lignin in the form of black liquor. This black liquor is used for power generation, chemical recovery and process steam in the pulp mill [25]. The black liquor can be gassified to create some few value added products in the pulping mills. The gasification can also generate power in large scale. Thanks to the technology, lignin now has transit into a major stream process in bio-refinery. It is no longer a fuel, but is a green fuel, it can be converted into mixed alcohols, ethanol, and other syngas products. Now, the application and research on lignin has extends to high-molecular weight applications and research is being made for its utilization as aromatic products $[26,27]$.

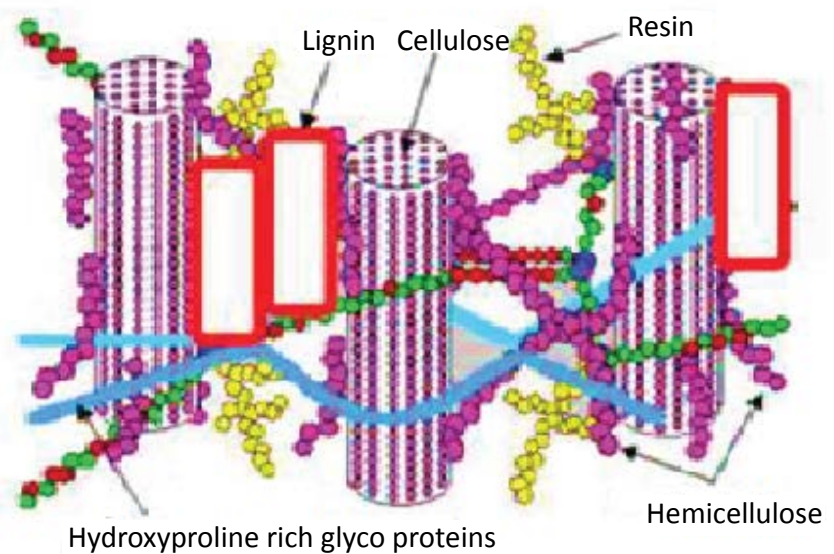

Figure 1: Wood microscopic structure showing the lignin position within lingocellulosic matrix [24].

\section{Disposal of Lignin in Black Liquor}

One of the waste products generated by the alkaline Kraft process in wood pulping is known as black liquor. It is a highly viscous aqueous waste consisting of organics constituents extracted from wood as well as inorganic pulping chemicals [27]. The solid composition of black liquor varies between $15 \%$ and $40 \%$ in weight out of which $30-40 \%$ is lignin $[28,29]$. Though the annual amount of lignin generated from black liquor is high [19], only about $10 \%$ of the lignin is recovered [20]. The rest are burnt during the extraction. The black liquorlignin helps in increasing the Kraft- recovery system and increases its pulping capacity. Therefore, if lignin is left untouched without a proper treatment, it can harm the environment and human because lignin can increase the biological oxygen demand (BOD) and chemical oxygen demand (COD) when introduced to wastewater streams [30]. This can be averted as well as used as a great economic resource by extracting lignin from black liquor, and apply it in various areas such as combustible fuel gases or as a raw material for the production of activated carbons, phenols, etc. [31].

\section{Lignin as a Sacrificial Agent}

The importance of lignin was first highlighted in 1977, introducing salt lignosulfonate as a sacrificial agent. A laboratory study found that surfactant loss could be reduced significantly by pre-treatment of rock with a lignosulfonate preflush [17]. Subsequently, lignosulfonate was field tested in conjunction with the Glenn Pool surfactant flood expansion project [32,33]. Due to the success of lignosulfonate, another trend appeared to use raw source to replace it, this trend showed the importance of lignin as cheap raw source $[34,35]$.

Johnson Jr and Westmoreland [36] extend the work of sacrificial agent by a finding that showed sacrificial adsorbates can outperformed the use of surfactant and adsorb on potential adsorption sites in the formation matrix, and consequently reduce the overall surfactant adsorption as the emulsion progresses. They also found that preparation of ligosulfonates is expensive. Thus, they introduced sacrificial agent consisting of effluent derived from the caustic extraction stage or weak black liquor.

Dardis [37] studied the soda-anthraquinone lignin as a sacrificial agent for surfactant. He investigated its use as a pre-flood agent in a mixture with the miceller dispersion, and found that the sodaanthraquinone lignins are strongly adsorbed by the adsorption sites in the formation.

Howard and Stirling [38] found the E-stage bleach plant as an active agent that can prevent the adsorption of anionic surfactant (sulphonated oil type surface active agents) on clays and sandstones. However, the main disadvantage of the use of E-stage bleach plant effluent, is the low concentration of active ingredients in the liquid.

Naae and DeBons [39] create a more effective surfactant from lignin by poisoning hydrogenation catalyst with sulphur. The lignin phenols that are produced from the reduction reaction can be recovered from the reaction mixture with a suitable organic solvent such as benzene, toluene, ether or diethyl ether. Later on the same year, they discovered the importance of surface-active compound chemicals. Useful surfactants have been produced by investigating the ways to increase oil recovery by reducing the interfacial tension to improve the displacement ability of water floods to act between oil and water in the reservoir [40].

Morrow [41] stated that lignin derivatives can be prepared by dissolving brines in fresh water followed by an addition of other 
compounds. This is because divalent brines cannot solubilized lignin, thus it must be prepared in fresh water prior to use with lignin. However, this may become a disadvantage to the process since large volume of fresh water is needed.

Kieke [42] suggested that the surfactant mobilizes the oil remaining in place after conventional production and allows it to be swept into production wells. Lignin is a waste by-product that the pulping industry produces in prodigious amounts. As a result, a large research effort has been undertaken over the last 40 years in attempts to find uses for the large volume of lignin by-product. Lignin itself is a major non carbohydrate constituent of wood and woody plants. It functions as a natural plastic binder for the cellulose fibers and permeates the membranes.

\section{Findings and Conclusion}

The role of lignin in industrial applications is negative because it is considered a waste material from the production of polysaccharide component from plants. This creates a lot of disposal problems given the huge amount of lignin generated from several industries such as paper industries. However, the inherent properties of lignin being biodegradable, $\mathrm{CO}_{2}$ neutral, available abundantly in industrial waste, low in cost, and environmentally friendly, and having antioxidant, antimicrobial, and stabilizer properties makes it potentially attractive as a polymer composite.

The depletion of petroleum resources together with the increase in environmental awareness and demand toward sustainability and renewable resource has created concern among researchers to look for the best alternative renewable materials. Lignin then were discovered as potential component for polymer including surfactants and sacrificial agents.

Lignin has variety of use. It is not merely function as polymer composite, but also in other industrial sectors. However, the complexity of lignin structure may cause limitation in the application of lignin in industries. Thus, in order to fully utilised or manipulate the use of lignin, some studies began to propose techniques for the surface modification of lignins to make it compatible with other polymer matrices. The research are still new, thus is very expensive even at industrial scale. Also, careful consideration should be paid to gaining insight into the chemical and physical properties of lignin molecule.

In this review paper, the feasibility of using black liquor lignin as an environmentally friendly, low cost polymer composite, especially in the chemical EOR, is highlighted. Overall characteristics of lignin; derivatives, functions, applications, structure, extraction methods and bio-renewable properties in polymer composites matrices are the main focus. The latest trend and prospects in the utilization of ligninreinforced polymer composites were also highlighted.

\section{References}

1. Sheng J (2010) Modern chemical enhanced oil recovery: theory and practice: Gulf Professional Publishing, USA.

2. Amyx JW, Bass DM, Whiting RL (1960) Petroleum reservoir engineering: physical properties: McGraw-Hill College.

3. Lake LW (1989) Enhanced oil recovery.

4. Alvarado V, Manrique E (2010) Enhanced oil recovery: An update review. Energies 3: 1529-1575.

5. Robel R (1978) Enhanced oil recovery potential in the United States. Interstate Oil Compact Comm. Com. Bull. USA.

6. Donaldson EC, Chilingarian GV, Yen TF (1985) Enhanced oil recovery, I: fundamentals and analyses: Elsevier.
7. Pope GA (2007) Overview of chemical EOR. In: Presentation Casper Eor workshop.

8. Watkins C (2009) Chemically enhanced oil recovery stages a comeback Inform 20: 682-685.

9. Thomas S (2006) Chemical EOR: The past-does it have a future? (Russian)

10. Bera A, Kumar T, Ojha K, Mandal A (2013) Adsorption of surfactants on sand surface in enhanced oil recovery: isotherms, kinetics and thermodynamic studies. Applied Surface Science 284: 87-99.

11. Dabrowski A (2001) Adsorption-from theory to practice. Advances in colloid and Interface Science 93: 135-224.

12. Southwick JG, Buijse MM, Van Batenburg DW, Van Rijn CHT (2014) Enhanced oil recovery fluid containing a sacrificial agent. Google Patents.

13. AIQuraishi AA, Alsewailem FD (2011) Adsorption of guar, xanthan and xanthanguar mixtures on high salinity, high temperature reservoirs. In: Offshore Mediterranean Conference and Exhibition, Italy.

14. Flaaten A, Nguyen QP, Pope GA, Zhang J (2008) A systematic laboratory approach to low-cost, high-performance chemical flooding. SPE Symposium on Improved Oil Recovery, USA.

15. Shamsijazeyi H, Hirasaki G, Verduzco R (2013) Sacrificial agent for reducing adsorption of anionic surfactants. SPE International Symposium on Oilfield Chemistry.

16. Gogoi SB (2011) Adsorption-desorption of surfactant for enhanced oil recovery. Transport in Porous Media 90: 589-604.

17. Kalfoglou G (1977) Lignosulfonates as sacrificial agents in oil recovery processes. Google Patents.

18. Muherei MA, Junin $R$ (2009) Equilibrium adsorption isotherms of anionic nonionic surfactants and their mixtures to shale and sandstone. Modern Applied Science 3: 158.

19. Tejado A, Pena C, Labidi J, Echeverria J, Mondragon I (2007) Physicochemical characterization of lignins from different sources for use in phenolformaldehyde resin synthesis. Bioresource Technology 98: 1655-1663.

20. Calvo-Flores FG, Dobado JA (2010) Lignin as renewable raw material. Chem Sus Chem 3: 1227-1235

21. Carrott $P$, Carrott MR (2007) Lignin-from natural adsorbent to activated carbon: a review. Bioresource technology 98: 2301-2312.

22. Ek M, Gellerstedt G, Henriksson G (2007) Ljungberg Textbook: Pulp and Paper Chemistry and Technology: Fibre and Polymer Technology, KTH.

23. Vishtal A, Kraslawski A (2011) Challenges in industrial applications of technical lignins. BioResources 6: 3547-3568.

24. Agrawal A, Kaushik N, Biswas S (2014) Derivatives and applications of ligninan insight. The Sci-Tech Journal 1: 30-36.

25. Zaied M, Bellakhal N (2009) Electrocoagulation treatment of black liquor from paper industry. Journal of Hazardous Materials 163: 995-1000.

26. Jin W, Tolba R, Wen J, Li K, Chen A (2013) Efficient extraction of lignin from black liquor via a novel membrane-assisted electrochemical approach. Electrochimica Acta 107: 611-618.

27. Demirbas A (2008) Recovery of oily products from organic fraction of black liquor via pyrolysis. Energy Sources, Part A 30: 1849-1855.

28. Cardoso M, De Oliveira ÉD, Passos ML (2009) Chemical composition and physical properties of black liquors and their effects on liquor recovery operation in Brazilian pulp mills. Fuel 88: 756-763.

29. Zhao XY, Cao JP, Morishita K, Ozaki J, Takarada T (2010) Electric doublelayer capacitors from activated carbon derived from black liquor. Energy \& Fuels 24: 1889-1893.

30. Lataye DH, Mishra IM, Mall ID (2006) Removal of pyridine from aqueous solution by adsorption on bagasse fly ash. Industrial \& engineering chemistry research 45: 3934-3943.

31. Kohl AL (1986) Black liquor gasification. The Canadian Journal of Chemical Engineering 64: 299-304.

32. Angert P, Leventhal S (1985) Preflush analysis of the Glenn Pool Surfactant Flood Expansion Project. SPE Annual Technical Conference and Exhibition. 
Citation: Sulaiman WRW, Abbas AH, Jaafar MZ, Idris AK (2016) Investigating the Lignin Black Liquor in Chemical Enhanced Oil Recovery: A Review for Sacrificial Agent. J Pet Environ Biotechnol 7: 298. doi: 10.4172/2157-7463.1000298

Page 4 of 4

33. Bae J, Petrick C (1986) Glenn pool surfactant flood pilot test: Comparison of laboratory and observation-well data. SPE Reservoir Engineering 1: 593-603.

34. Wang H, Zou J, Shen Y, Fei G, Mou J (2013) Preparation and colloidal properties of an aqueous acetic acid lignin containing polyurethane surfactant. Journal of Applied Polymer Science 130: 1855-1862.

35. Cerrutti B, De Souza C, Castellan A, Ruggiero R, Frollini E (2012) Carboxymethy lignin as stabilizing agent in aqueous ceramic suspensions. Industrial Crops and Products 36: 108-115.

36. Johnson JS, Westmoreland CG (1982) Sacrificial adsorbate for surfactants utilized in chemical floods of enhanced oil recovery operations. Google Patents.

37. Dardis RE (1985) Soda-anthraquinone lignin sacrificial agents in oil recovery. Google Patents.
38. Howard J, Stirling M (1987) Sacrificial agents for enhanced oil recovery Google Patents.

39. Naae DG, DeBons FE (1988) Recovering hydrocarbons with water soluble alkylphenol lignin surfactants. Google Patents.

40. Naae DG, Whittington LE, Ledoux WA, DeBons FE (1988) Recovering hydrocarbons with surfactants from lignin. Google Patents.

41. Morrow LR (1992) Enhanced oil recovery using alkylated, sulfonated, oxidized lignin surfactants. Google Patents.

42. Kieke DE (1999) Use of unmodified kraft lignin, an amine and a water-soluble sulfonate composition in enhanced oil recovery. Google Patents. 